\title{
¡YA NO ESTÁS EN LA CASA! TECNOLOGÍAS DE LA ESCOLARIZACIÓN
}

\author{
Alberto Martínez Boom \\ Universidad Pedagógica Nacional, Colombia.
}

$\cos \infty$

\section{JÁ NÃO ESTÁS EM CASA! \\ TECNOLOGIAS DE ESCOLARIZAÇÃO}

\section{Resumo}

O fenômeno da escolarização pode ser analisado por diferentes abordagens. Alguns o estudam como um fato, outros o observam como uma decisão política, outros ainda estão interessados em sua função social como um fator de inclusão. Este trabalho não trabalha com esses registros. Procura se deter mais na descrição de certos detalhes dos começos; por isso o uso de fontes primárias e documentos de época, para mostrar o processo que conecta o surgimento da escola pública com a expansão da escolarização como dispositivo governamental, ou seja, uma prática que passa por descrever minúcias do espaço e do tempo de escola, a geometrização do corpo infantil, a ênfase na sua quietude e obediência como caminhos de escolarização que podem ser entendidos e associado a uma ortopedia moral.

Palavras-chave: escolarização, ortopedia moral, planos de escola, geometrização do corpo.

\section{YOU ARE ALREADY IN THE HOUSE! TECHNOLOGIES OF SCHOOLING}

\begin{abstract}
The phenomenon of schooling can be analyzed from diverse approaches, some of them study it like a datum, some see it like a political decision, some others are interested in its social function as an inclusion factor; this work does not include those perspectives. It is better focus on the description of certain details of the beginning, for that reason the use of primary sources and documents of the epoch, to show the process that links the emergence of the public school with the wideness of the schooling like governmental mechanism, which means, a practice that describes the trifles of the school space and time, the geometrization of the infant body, the insistence on his quietness, stillness and obedience like principles of a schooling that can be understood and associated to a moral orthopaedics.

Key-words: schooling, moral orthopaedics, school plans, body geometrization.
\end{abstract}




\section{¡YA NO ESTÁS EN LA CASA! \\ TECNOLOGÍAS DE LA ESCOLARIZACIÓN}

Resumen

El fenómeno de la escolarización puede ser analizado desde diversos enfoques, algunos la estudian como dato, otros la miran como decisión política, algunos otros se interesan en su función social como factor de inclusión; el presente trabajo no va por estas vías. Importa mejor detenerse en la descripción de ciertos detalles del inicio, por eso la utilización de fuentes primarias y documentos de época, para mostrar el proceso que conecta la aparición de la escuela pública con la ampliación de la escolarización como dispositivo gubernamental, es decir, una práctica que pasa por describir minucias del espacio y del tiempo escolar, la geometrización del cuerpo infantil, la insistencia en su quietud y obediencia como derroteros de una escolarización que puede ser entendida y asociada a una ortopedia moral.

Palabras-clave: escolarización, ortopedia moral, planes de escuela, geometrización del cuerpo.

\section{VOUS N'ÊTES PAS DÉJÀ À LA MAISON ! TECHNOLOGIES DE L'ESCOLARISATION}

\section{Résume}

Le phénomène de la scolarisation peut être analysé par des approches différentes. Certaines les études comme un fait, d'autres notent qu'une décision de politique, d'autres sont intéressés à leur rôle social comme un facteur d'inclusion. Ce travail ne se développe pas dans ces enregistrements. Importe les déscritions des certains détails des débuts, c'est pourquoi l'utilisation de sources primaires et les documents de l'époque, à montrer le processus qui relie l'émergence de l'école publique avec l'expansion de scolarisation comme dispositif gouvernemental, c'est-àdire, une pratique qui passe par décrire les menus détails d'espace et de temps à l'école, la géométrie de corps de l'enfant, l'accent mis dans son immobilité et l'obéissance comme les chemins de la scolarisation qui peuvent être compris et associés de l'orthopédie moral.

Mots-clé: éducation, orthopédie moral, plans scolaire, la géométrie de corps.

os discursos sobre la escolarización de la población exigen tratamiento
histórico o mejor, vías de análisis posible que nos hagan observar de cerca
los nexos y distancias que van de la forma escuela a la escolarización como
dispositivo que esclarece la conformación de esta práctica moderna, es decir, un tiempo y un espacio común donde prolifera la educación como asunto estratégico y productivo.

Atrás quedaron las posibilidades de las escuelas parroquiales, de la enseñanza particular y de otros escenarios de la vida privada cuya laxitud e individualización distan, y por mucho, de la novedad derivada de su acontecimiento como fenómeno público. Lo cierto fue que los primeros intentos de normalización de la enseñanza simultánea, con sus tiempos y espacios comunes dieron lugar a una forma distinta de educar y de enseñar.

Las fuerzas que se apropian de la forma escuela constituirán acciones sobre acciones posibles que vale la pena resaltar: distribuir en el espacio, ordenar y subdividir

\begin{tabular}{|l|l|l|l|l|l|} 
Hist. Educ. (Online) & Porto Alegre & v. 16 & n. 38 & set./dez. 2012 17-42
\end{tabular}


en el tiempo, programar los actos, producir subjetividades tanto para el enseñante como para el escolar, suscitar prácticas y reiteraciones, cumplir normas, etc.

Estas líneas de fuerza operan como disposiciones cuyos contornos no están claramente definidos, simplemente atraviesan las dispersiones que conforman la escolarización como dispositivo general y la escuela como dispositivo secundario. La narración de la forma como se fue configurando el proceso de escolarización esta referido en este texto a un espacio que podríamos nombrar como la América hispánica.

Para Hervás y Panduro (1789), quien veía en la educación civil la religión de la sociedad, todo el pueblo debía instruirse en la escuela de primeras letras, sin importar su condición o escala social, con el propósito de que aprendieran fundamentalmente a vivir en sociedad como seres civilizados:

El número de escuelas debe corresponder al pueblo de toda la nación, pues todo él según la política no ya cristiana, más civil, debe asistir a ellas. El más infeliz artesano o labrador debe aprender a leer, contar y escribir, pues el conocimiento de todas estas tres cosas es una cosa esencialmente necesaria para todo miembro de la sociedad humana, si ha de vivir en ella. Las naciones civiles se distinguen de las menos civilizadas, y estas de las bárbaras en tener dicho conocimiento, que además de la civilización, trae la felicidad al Estado [...] siendo las primeras escuelas esencialmente necesarias para que los infantes sean miembros útiles y civiles de la sociedad humana, toca al gobierno público su fundación en todo país habitado, para que todas las clases de la República puedan aprovecharse de un bien, que debe ser común. (Hervás y Panduro, p. 287)

La escolarización conecta, de manera estratégica, lo pedagógico con lo político y pone a hablar los procesos sociales en su pugna por el poder. Habría que intentar, por tanto, una conceptualización múltiple y no unívoca de este concepto, lo que significa detenernos en algunos de los detalles cotidianos que muestran a la escolarización funcionando como mecanismo de normalización de las poblaciones, es decir, como práctica que hace que algo sea aceptado como normal.

Detenernos en las singularidades de la escuela pública como acontecimiento social y político supone cierto nivel de asombro respecto de las prácticas que siendo novedosas en su época hoy nos parecen evidentes y naturales; una especie de velo que oculta la trama de lo que cambia.

\section{El espacio-tiempo escolar}

Antes de la expulsión de la comunidad jesuítica en España y en la América hispánica existían prácticas de enseñanza, dispersas y algo ambiguas, llevadas a cabo en diversos lugares, sin que ningún espacio en particular fuera identificado como propio para 
aquella práctica. La instrucción doctrinal por ejemplo, se ejecutaba en cualquier parte de la encomienda; la enseñanza doméstica en la casa del discípulo que puede pagar un preceptor particular; el artesano utilizaba su taller como lugar de enseñanza al igual que el peluquero o el sastre.

En el momento en que aparecen las prácticas y los discursos que posibilitaron la irrupción de la escuela pública, varias voces empezaron a clamar por la separación de la instrucción de primeras letras de las demás actividades y escenarios de la vida ordinaria.

Simón Rodríguez, por ejemplo, criticaba a los padres que fiaban la educación de sus hijos a cualquier vecino medianamente instruido, decía escuetamente: "basta para conocerlo fijar un poco de atención en las peluquerías y barberías que sirven de escuela; y sin detenerse en examinar su método, ni la habilidad de sus maestros, pásese a averiguar con qué autoridad se han establecido, quiénes son sus discípulos y qué procesos hacen" (Rodríguez, 1999, p. 204).

Semejante crítica era a la vez una solicitud a favor del nombramiento de maestros públicos, regulados por el virreinato, para que se ocuparan de la enseñanza de los niños, al tiempo que se hacia necesario que hubiese un espacio propio para esta labor.

La escuela como escenario exclusivo o particular de la enseñanza fue apareciendo esporádicamente en los discursos, principalmente en todos aquellos que recomendaban la instrucción de los menores pobres como el paliativo de las miserias y las necesidades del Estado. En este proceso de edificación del espacio escolar, aparece lo que se conocerá como "planes de escuela" ${ }^{1}$ los cuales contribuyeron enormemente a la objetivación de este nuevo lugar. Así, ella fue saliendo de la bruma espesa, de las menciones erráticas y difusas, para emerger, lentamente por cierto, como figura tangible y real, disímil a otros espacios tanto públicos como privados, en particular, la iglesia, la casa, el taller y el hospicio.

La afinidad de la escuela con otras prácticas de recogimiento y encierro le permitió adquirir una espacialidad contingente. Aislar, preservar y proteger se fueron asociando sutilmente a las funciones de la instrucción, lo que delimitaba la escuela como un espacio que mantiene de cierta manera alejada a los infantes de los vicios, los ruidos, las tentaciones o la corrupción. Tal era el pedido de Juan Luis Vives al afirmar que

lo más conveniente [era] establecer la escuela fuera de la ciudad, sobre todo si [esta era] marítima o habitada de comerciantes; no siendo tampoco

\footnotetext{
1 "Escritos casi siempre por curas párrocos, los planes de escuela, generalmente contenidos en un expediente, evidencian la compleja relación entre los poderes civiles y eclesiásticos en el establecimiento y administración de la enseñanza de las primeras letras" (Martínez Boom, 2011, p. 33).
} 
a propósito el paraje donde [salieran] a pasear los ociosos, ni cerca de caminos frecuentados. (Vives, 1923, p. 40)

De este modo, se fue perfilando un "adentro" que tras los muros infranqueables de la escuela, debía mantener a los infantes protegidos de los peligros del "afuera". El espacio sería claramente cercado pero no sólo constituyéndose como un espacio físico sino también como un espacio social y diferenciado al interior de la escuela. De esta forma se fue convirtiendo en un espacio totalmente distinto, nuevo ${ }^{2}$ y diferenciado.

La paulatina configuración de sus límites permitió a su vez la aparición de unos sujetos identificados como sus habitantes naturales: el maestro y los alumnos. El lugar común destinado a la enseñanza de los infantes fue ganando en estabilidad así en principio no siempre se erigiera un lugar propiamente construido para este fin. De todas maneras, con edificio propio o $\mathrm{no}^{3}$, la escuela - aún como mera denominación - disputó y ganó al resto de lugares la primacía de la enseñanza.

La ordenación interna de la escuela en un límite segmentado y acotado, en el que hay una coordinación cronométrica de las principales actividades, con cuerpos conscientemente ubicados en el espacio para la ritualización de sus actividades, cada una de ellas regulada y vigilada permite considerar, siguiendo a Antonio Caballero y Góngora, “a los niños separados ya del seno y de la disciplina de sus Padres" (Martínez, 2011, p. 100).

El niño ya no estaba en su cálido hogar sino en otro lugar que, como anota Ariès, supone una separación, del mundo de los adultos como en una especie de cuarentena, este largo periodo de reclusión de los niños, en cierto modo equiparable al encierro que empezaron experimentar los locos, los pobres y las prostitutas, se conoció como escolarización (Ariès, 1987, p. 11-12), en otras palabras, la escuela es una etapa que se diferenció claramente de la casa.

Con la escolarización se produjo, entonces, la definición de lo que en adelante fue considerada la primera edad, susceptible de intervención, modelaje y seguimiento, produciéndose también la segregación de los menores (minoridad) mediante los procedimientos de alojar a dichos sujetos en lugares ad hoc bajo el cuidado de cierto sujetos (el cuerpo del enseñante), por varias horas al día, durante cierta porción del año.

\footnotetext{
${ }^{2}$ La escuela de pardos de Caracas especificó de manera tajante que el único lugar donde se debía enseñar era la escuela, a tal punto de multar al que instruyese a los niños en un lugar diferente. Al respecto se estipulaban "que no se [permitiría] que las tiendas de barberos, sastres, peluqueros, etc., ni en casas particulares se [enseñaran] niños de clase a leer, escribir y contar tasándose al contraventor multa" (Archivo del Consejo Municipal de Caracas. Expediente sobre escuelas, s.f.).

3 En el plan de escuela de Girón el padre Felipe Salgar estableció que de no poder acceder a un edificio público para hacer escuela, se utilizara la sala de la casa del maestro, demarcando de todas formas la disposición de los infantes, la cual emulaba el orden que usualmente se adoptaba en otros espacios sociales como las iglesias o las plazas públicas (AGN, Colonia, Colegios, t. 2, f. 950r-950v).
} 
Espacio de encierro que en su propio límite produjo unas formas específicas de subjetividad: escolares, alumnos, cadetes, niños, decuriones, aprendices, empollones, discípulos, etc., hechos a la medida de cada modelo y de cada lugar.

La novedad de aquel lugar demarcaba fronteras no sólo hacia "afuera" también lo hacía hacia "adentro", me refiero a los espacios sociales que debían respetarse y nunca traspasarse. Felipe Salgar, cura de la villa de Girón, proponía en su plan que los infantes de todas la clases sociales debían acudir a la escuela a aprender los primeros rudimentos, sin embargo, es enfático en establecer que las diferencias de estirpe debían estar claramente trazadas en el aula de clase:

Se hará en la sala más grande de la casa del maestro una división, que consistirá en separar los bancos o escaños de la testera superior de los de la inferior, dejando entre unos y otros una media vara de intermedio. Servirá esto para denotar que los niños nobles ocupan las bancas de arriba y los plebeyos y gentes de castas las de abajo. (AGN, Colonia, Colegios, t. 2, f. 950r-950v)

Los niños aprenderían desde su tierna edad que en el ordenamiento espacial, incluso el escolar, debían conservarse las relaciones de poder, tal como sucedía con la distribución espacial al interior de la iglesia, pues los poderes de la ciudad estaban claramente diferenciados allí; al celebrarse los actos litúrgicos los neogranadinos prestantes se debían ubicar más cerca al atrio, mientras que los de castas inferiores debían ubicarse hacia a la salida de la iglesia. En el aula de clase, tanto los niños nobles como los plebeyos debían aprender que en el espacio cada uno debía tener un lugar diferenciado en el que ambas castas sabían cuál era la privilegiada.

El espacio social que nació en la escuela traspasó en algunos casos la frontera del "adentro", pues cosas que eran propias de esta fueron llevadas a la casa gestándose una especie de escolarización del hogar. Me refiero particularmente a las prácticas del "buen vasallo" y del "buen cristiano" que el maestro vigilaba que sus infantes mantuviesen como normas de vida civil. Así lo señala el expediente sobre la aprobación de una escuela de primeras letras para la enseñanza de los pardos en la ciudad de Caracas,

que dará reglas [al maestro] a la moderación y compostura con que los discípulos deben conducirse de sus casas a la escuela, y de éste a aquella, y cada cuando salgan a la calle, corrigiendo con prudencia y tesón lo que los haga entrar en no causar incomodidades a los vecinos con juegos y arrojamiento de piedras en la calle, con perjuicio de las fábricas, o edificios. (Martínez Boom, 2011, p. 87)

Las fronteras de la escuela constituyeron también un lugar de encierro, aunque no hubiese barrotes, las paredes de las aulas no podían ser franqueadas. Encierro infantil 
que podemos asociar a la imagen conventual pero en dirección muy diferente, importaba formar en la vida tanto civil como cristiana bajo prácticas de policía a fin de formar vasallos obedientes, leales al soberano y útiles al reino tal y como lo dice el plan de escuela del padre Miranda:

La educación de los primeros años es la piedra angular sobre que carga todo el peso de las obligaciones del hombre así es que debe precisamente dividirse en la doctrina que mira la religión y en poner aptos a los jóvenes para seguir el camino de la vida civil siendo útiles al Rey, a la patria, y a los conciudadanos. (AGN, Colonia, Colegios, t. 3, f. 823v-824r)

En los planes también se disponía la repartición del tiempo escolar. El tiempo determinaba en primera instancia una fracción general:

Todos los vecinos que tengan algún hijo, que manifieste alguna habilidad desde dicho día lo mandarán a la escuela, desde las siete de la mañana hasta las once del día y por la tarde desde las dos hasta las cinco. (AGN, Colonia, Colegios, t.3, f.821r).

En lo específico determinaba también una rutina que debía seguir cada niño en el transcurso del día en la escuela, es decir, que se producía un régimen donde el maestro sabía lo que estaba haciendo su discípulo como lo expresa el plan de estudios generales de Caballero y Góngora:

Las lecciones diarias deben tenerse desde las siete y media de la mañana (en que ya los niños habrán oído misa y desayunado) hasta las once, y desde las dos y media hasta las cinco: dándoseles un rato de diversión según lo propuesto en el estudio general. (Martínez Boom, 2011, p. 108)

Si bien la escuela es la primera institución estatal del saber, sus conexiones con la iglesia fueron desde sus inicios muy visibles, incluso difíciles de separar, el tiempo escolar en particular pone en evidencia su estrecha relación con los tiempos del convento y su lenta especialización hasta llegar al horario que constituye, por supuesto, toda una novedad.

No deja de sorprender constatar como las rutinas de los menores, abarcan tanto el interior como el afuera de la escuela:

Antes de la seis se recogerán todos los niños en la escuela para ir en comunidad a oír misa de seis en la iglesia del colegio [...] a las once se irán a sus casas y cuidará el maestro que salgan con silencio y compostura [...] se enseñará también el andar a misa y les instruirá reglas de política y buena crianza. (Martínez Boom, 2011, p. 62)

Lo cotidiano se inventa en esos detalles de articulación espacio temporales y se enuncian en el plan para reglamentar las prácticas como 
una coerción ininterrumpida, constante, que vela sobre los procesos de la actividad más que sobre su resultado y se ejerce según una codificación que reticula con la mayor aproximación el tiempo, el espacio y los movimientos. (Foucault, 1987, p. 141)

\section{Una ortopedia moral}

A partir de la segunda mitad del siglo 18 se aprecia claramente en los métodos y reglamentos estipulados en los planes de escuela de primeras letras y en los documentos referentes a la fundación de las mismas, el tipo de horma moral que los niños debían aprender en aras de convertirse en ciudadanos virtuosos. En el método de Joset Domingo Duquesne de la Madrid (1785) se conecta sin ninguna ambigüedad la aspiración moral con el tiempo de la infancia, cuya

edad [es] la más susceptible de buenas y malas impresiones y [...] el tiempo más crítico para los hombres, [...] en que comienzan a brotar las pasiones, deberá el maestro arreglar su vida, por una conducta seria y juiciosa, que pueda servir de regla a sus discípulos y baste por sí misma a contener los ímpetus de la primera edad. Y para inspirarles la devoción que debe ser la leche de todos los cristianos. (Hernández de Alba, 1983, p. 37)

Los discursos prescriptivos de la escuela no fueron sólo palabras o reliquias literarias, fueron también documentos en donde la vida social adoptó formas definidas, patrones a seguir que se presentaron como referentes o espejos que los individuos imitaron hasta ser interiorizados como normas de vida, traducidos en gestos, actos, costumbres, hábitos que la repetición terminó por convertirlos en estilos de vida y modos de proceder. El cuerpo del niño empezó a ser blanco privilegiado de discursos y acciones.

La preocupación por el gobierno de los niños en humanistas como Juan Luís Vives primero y posteriormente en reformadores como Jovellanos, Campomanes o Cabarrus, constituyó un dispositivo fundamental para definir ese estado de tiempo llamado primera edad.

La innovación principal que produjeron estos reformadores ilustrados del siglo 18 parte del establecimiento de una edad temprana para la instrucción que será en adelante diferente y previa a la clásica educación de la juventud. En esta tierna edad ha de realizarse unos procesos de instrucción y prácticas de crianza mediante los cuales se pudieran modelar y formar unos cuerpos que eran considerados dúctiles y maleables, o en palabras de Huarte de San Juan eran "cera blanda, arcilla todavía húmeda, arbolito tierno, campo baldío".

Este estadio de la vida llamado infancia jugó un papel fundamental en la constitución de un tiempo subjetivo separado del tiempo real. Por supuesto esta separación del sujeto 
con la naturaleza lo alejó cada vez más de las relaciones con la vida y con el mundo y lo convirtió en un objeto que era necesario civilizar, es decir, regular como una subjetividad específica (alumno, estudiante) con características determinadas.

Cabe advertir que esta es una vía de ejercicio de poder, si eres sujeto de, estas sujetado a, estás vinculado sin que necesariamente este actuando un director permanente, sino mediante procesos disciplinarios que definieron, ciertas parcelaciones arbitrarias del tiempo, recortes espaciales que limitaron la movilidad, ejercicios y tareas que instalaron la rutina como modo de vida y, en fin, la construcción de unos cuerpos que tuvieron como meta final, después de algunos años de instrucción, el propósito de dedicarse al trabajo, estar dispuestos a la obediencia y por supuesto a convertirse en sujetos virtuosos.

Entonces, para que la construcción del cuerpo del niño bajo una moldura moral específica fuese efectiva, "los padres, y maestros" debieron trabajar

continuamente en alimentar, y hacer crecer estas débiles semillas del bien, restos preciosos de la antigua inocencia, arrancando con cuidado infatigable las zarzas, y espinas, que brotan sin cesar en terreno tan mal acondicionado. (Rolin, 1755, p. 16)

En esta metáfora recurrente, del plantío o del fruto, entre los hombres del periodo que nos ocupa, era al maestro a quien le correspondía

recoger a buen tiempo el ánimo de los niños, meterles ya como en regla, hacerles más dóciles, y sumisos, y estorbarles la disipación tan contraria a veces a la salud del cuerpo, como a los progresos del entendimiento. (Rolin, 1781, p. 4)

El maestro en su función tuvo la labor no sólo de encausar al menor en los principios del hombre virtuoso, sino también de librarle del daño que éste pudiera infringirse a si mismo durante aquel momento de incompletud de la vida.

La infancia era peligrosa para sí misma lo que justifica la necesidad de la crianza y de la conducción. Así, se empezó a naturalizar la idea de que la educación debía comenzar en la tierna edad, estableciendo la relación infancia-educación como el universal que hoy nos rige. Con este se construyen igualmente los universales de la justicia o de la virtud como funciones de la escuela, aunque desde luego, no era la primera vez que aparecía la escuela con la finalidad de formar hombres virtuosos.

Ciertamente Locke, entre otros, ya habían advertido que: "la base de todas las virtudes consiste en estar capaces y dispuestos para vencer todos los deseos y reprimir todas las pasiones, siguiendo puramente lo que la razón proponga" (Locke, 1767, p. 27). 
Desde entonces se hizo indispensable acostumbrar el espíritu de los niños "a una buena disciplina y forzándole a que se someta a la razón desde el principio" (Locke, 1767, p. 69). El tortuoso y lento proceso de instrucción moral debía impartirse a los menores mediante la imposición de ejercicios rutinarios, pues "por más que se hagan sonar incesantemente en sus oídos las reglas y las máximas, no hay que esperar fruto alguno [...] hasta que la práctica los haya reducido al hábito" (Locke, 1767, p. 24). De este modo, "la principal cosa a que se debe atender en la educación de los niños, es a los hábitos que se les haga contraer en un principio" (Idem, p. 41), pues era más fácil transformar la naturaleza que transformar un hábito.

En ese sentido, la educación escolar, que más tarde conoceremos como escolarización, desempeñó una función inmanente y constitutiva en el proceso de gestación de sujetos que asumieron unos tipos de comportamiento y de relación con el trabajo, el saber, la vida y jugaron un papel fundamental en la constitución de un tipo particular de sociedad y no solo una función superestuctural o de reproducción de la ideología dominante y de afianzamiento de las clases sociales.

Desde esta perspectiva, la educación no fue una práctica social derivada del sistema productivo o determinada por las relaciones sociales de producción, sino que ella fue constitutiva de realidad social como también de un tipo especial de sujeto dispuesto como buen vasallo y buen cristiano, que estuvo en la obligación de trabajar o por lo menos ser útil socialmente. En últimas, la escuela no preparaba al trabajador, producía lo que lo disponía moralmente para el trabajo:

Dos aspectos tiene la educación moral: uno mira a formar el espíritu humano según las leyes y costumbres racionales de la crianza civil y política; otro mira a formarle según las máximas que dicta la razón y con nueva perfección enseña la religión [...] La educación civil es la religión profana de la sociedad humana; en esta el pagano con buena educación civil se hace respetar y estimar más que el cristiano mal criado. No se espere jamás que el hombre que no ha tenido la educación civil, la aprenda con los libros [...] tampoco se espere que un infante aprenda la educación civil si no la ve practicar. La experiencia enseña, que la educación civil se aprende solamente en los años de la infancia y niñez, y que el ejemplo entonces es la voz viva y eficaz. [A lo sumo,] la educación moral comprende las máximas de la razón natural, y los dogmas y disciplina de la religión revelada." (Hervás y Panduro, 1789, p. 278-281)

El ejemplo conectó así al maestro y al alumno, al perfilar un sujeto referente por medio de la práctica que aparece como inexpugnable: "los maestros no sólo deben saber mucho para poder enseñar bien, sino tener la aptitud y habilidad necesarias; ser de costumbres puras, y su principal cuidado el de no decir ni hacer cosa que traiga mal ejemplo a los oyentes" (Vives, 1923, p. 41). 
Para Amar y Borbón la educación moral era la más difícil de impartir a los niños, "pero también las más importante, porque abraza la enseñanza e ilustración del entendimiento, la regla y dirección de las costumbres, y en una palabra lo que se llama buena conducta y manejo en todas las acciones" (Amar y Borbón, 1790, p. 100).

La instrucción de los niños intentaba sacar el mayor beneficio del saber que le proporcionaban pensadores clásicos como Platón, Quintiliano, Aristóteles, Plutarco, Séneca, a los que citaban continua y abusivamente para que su autoridad quedara libre de toda sospecha. Se configuró "un catecumenado privilegiado: la infancia" (Varela y Álvarez, 1991, p. 18), y estableciendo la semejanza con la República de Platón, consideraban que debía dárseles instrucción y crianza según se tratara de uno u otro tipo de niño con lo cual señalaban las diferencias de clase o estamento.

Se construyó lentamente toda una "cartografía diversificada de la infancia" (Idem, p. 18). dependiendo de las calidades de naturaleza de los sujetos lo que exige programas educativos diferenciados en la escuela. Esta clasificación contendrá diferentes infancias que abarcan desde la infancia principesca, pasando por la infancia de los hijos de las clases principales, hasta la infancia ruda de las clases populares.

Por cierto que existieron diferencias importantes respecto de los períodos denominados como infancia o respecto al momento en que era conveniente comenzar a enseñar la doctrina cristiana, la policía o las letras; pero en lo que si hubo total acuerdo era en la necesidad de que desde muy pronto se iniciara en el aprendizaje de la fe y las buenas costumbres.

Como ya indicamos, la tierna edad significaba: maleabilidad, debilidad, minoridad, incompletad y flaqueza. De cada una de ellas se derivaron correctivos, terapéuticas y en general reglas morales y físicas para su arreglo. Así de la maleabilidad se desprendió la capacidad para ser modelada; de la debilidad se justificó la guía del adulto o tutela; de la minoridad se desprendió la necesidad de identificarlo con los adultos y por lo tanto se precisó su civilización; de la flaqueza de juicio la exigencia de desarrollar la razón, para que se distinguiera de las bestias; $y$, en fin, un proceso rígido y estricto de encauzamiento y disciplinamiento.

Todos aquellos que escapaban a las prácticas de adiestramiento del cuerpo o de las aptitudes se convirtieron en un problema para el Estado, puesto que se creía que atentaban contra las "buenas costumbres" y "la moral" de la sociedad (Foucault, 1996, p. 62), surge así la figura del "incorregible" que será contemporánea a la puesta en práctica de las técnicas de disciplina que tuvieron lugar principalmente en el ejercito, en los colegios, en los talleres y posteriormente, en las familias. 
De manera similar la "cruzada contra la masturbación" del niño, implicó una "cuadriculación discursiva del deseo sexual" y del "cuerpo sensual" que estuvo reforzada a su vez por la obligación de la confesión de los sacramentos y con las prácticas de interrogatorios sutiles hacia los menores (Foucault, 1996, p. 63). También será el alma la que empezará a ser "requerida para dar cuenta de la imperfección de los cuerpos y de las conductas, para aplicarse a dirigirlas mediante una sana regulación de los flujos" (Donzelot, 1979, p. 18). El alma, la conciencia, tenían que dirigir sistemáticamente las acciones del cuerpo. En la escuela se forma el alma, la virtud, porque el cuerpo es propenso al pecado.

Todo este conjunto de acciones constituyeron la instrucción y crianza de los menores, dispositivo que se denominó ortopedia moral (Valera y Álvarez, 1991) mediante este no sólo se configuró la niñez, en un ámbito muy general y abstracto, sino que se definió una etapa especialmente idónea para ser troquelada, marcada y gobernada dando lugar a la aparición de dispositivos institucionales concretos que fundan un tiempo y un espacio específicos como anotamos anteriormente, los cuales no estaban dados ni eran un a priori.

Para esta constitución progresiva de la infancia contribuyeron la práctica de crianza e instrucción que se dio inicialmente en los hospicios, casas de expósitos, albergues, casas de doctrina, las cuales y por un complejo proceso devinieron en escuela.

Fue el Estado, a través de la escuela y en complicidad con la familia el encargado de impartir esta ortopedia moral, encaminada a formar a las nuevas generaciones de vasallos virtuosos tanto en los principios cristianos como civiles ${ }^{4}$. Esto no significó que la familia hubiera dejado de operar por completo como productor de la infancia. Simplemente el Estado entró a regular y a administrar las prácticas de crianza o la propia educación de primeras letras sobretodo de los niños pobres.

Así, la familia vigiló y cuidó de forma continua y minuciosa a sus miembros menores con la ayuda de nuevos instrumentos que en esta época vieron la luz como los tratados dirigidos a la institución de la familia en que se señalan los papeles que marido y mujer tenían que desempeñar respecto a los más variados asuntos: gobierno, relaciones entre

\footnotetext{
${ }^{4}$ A diferencia de Hervás y Panduro, Campomanes ponderaba la instrucción religiosa que pudieran recibir los menores sobre la formación civil, puesto que de la primera dependía la segunda: "La educación, en tanto debe fundarse en la religión, debe formar buenos cristianos. Un buen cristiano es además un buen vasallo. Así, un buen cristiano consultará su conciencia para vivir arreglado a los preceptos divinos y a la moral de Jesucristo. Es tan perfecta esta ley divina que no sólo modera las pasiones destempladas sino que enseña a respetar al Soberano y a los Magistrados que el Real nombre gobiernan al público. También dicta la caridad con sus semejantes, para no hacerles ofensas y aliviarles en sus verdaderas necesidades" (Rodríguez de Campomanes, 1978, p. 39).
} 
esposos, y, por supuesto, nutrición y cuidado de los hijos, tal como lo prescriben, por ejemplo, textos como los de Hervás y Panduro o Josefa Amar y Borbón.

A cambio de la custodia y protección, dichos manuales ofrecieron a los padres el amor, la obediencia y el respeto de sus hijos. A la madre le prometen, a cambio de su reclusión en el hogar los poderes de gobernar y regir la casa, morigerar al esposo, y sobre todo nutrir y educar a sus pequeñuelos, su más preciado tesoro: "la madre que no da la leche de sus pechos a su hijo no es sino media madre, y todavía menos si no lo educa e instruye en la religión cristiana y en las costumbres que exige su noble naturaleza".

Ahora bien, la familia se consolidó en su papel educador bajo la premisa de que los padres son "por naturaleza" los primeros maestros, sin embargo, será a través de una promesa: entrégame tu hijo y yo te devuelvo un ciudadano como se establece la alianza integrativa entre Estado y familia.

Uno de los argumentos más recurrentes en el pedido de establecimiento de escuelas de primeras letras fue el propósito de conjurar la inmoralidad de los niños, en especial, la ociosidad y la vagancia ${ }^{5}$. Así lo estipuló la Sociedad Patriótica de Amigos del País de Mompóx al proponer la fundación de una aula de gramática y una escuela de primeras letras en 1785, como una forma de frenar el vagabundeo de los jóvenes (Hernández de Alba, 1983, p. 41-46), igualmente el cabildo de la Villa de Medellín en 1801, solicita al gobierno virreinal, el establecimiento de una escuela de primeras letras, pues "la continua vagancia y relajación de costumbre [los convierte en] unos vasallos inútiles al estado"6.

Estas prácticas escolares y familiares fueron reforzadas con el discurso de la policía que en general se propuso como una acción civilizatoria y moralizante que incluyó la dirección espiritual $^{7}$, la multiplicación y generalización de temas relacionados con el niño Jesús, el ángel de la guarda, los niños modelo, los niños inocentes, los niños santos, el limbo de los niños, y la creación de fiestas religiosas entre las que sobresale la primera comunión.

\footnotetext{
${ }^{5}$ En 1787, los vecinos de Chiquinquirá pidieron al virrey el establecimiento de una escuela de primeras letras para que "no solamente podamos precaver a nuestros hijos de la ociosidad y libertinaje, sino también el verlos aprovechados de la tan recomendada circunstancia de que aprendan a leer, escribir y contar y con este insaciable deseo de que se críen con la debida educación para que logrando en su juventud estar revestidos de buena crianza y que con el cultivo que corresponde, se hagan apetecibles para ejercer los oficios de la república, la sociedad y otros que traen consigo el lustre y adelantamiento de la patria" (Hernández de Alba, 1983, p. 118).

${ }^{6}$ Archivo General de la Nación. Sección conventos. "Expediente Acerca de la Real Cédula por la cual se concede permiso para la fundación de convento franciscano". Tomo 52, fol. 431v.

${ }^{7}$ En los planes de escuela de primeras letras propuesto para los pueblos de Lloro y Quibdó, se estipuló que a los niños "se les enseñará la tabla, y explicará un punto de Ortografía y otro de Policía" y en cuanto a las niñas, se emplearán "en la costura, y oficios domésticos" (Martínez Boom, 2011, p. 341).
} 
De modo semejante, pero con más nivel coercitivo, esta ortopedia fue aplicada en los espacios femeninos. Las niñas estaban sometidas a una enseñanza más rígida e inflexible en los principios morales con relación a la instrucción masculina, puesto que éstas estaban destinadas a llevar su vida en los preceptos propios de la "mujer cristina" y "virtuosa"; símbolo de la "buena crianza". Esta educación consintió en aprender las "labores de mano del gobierno de una casa" (coser, cocinar, chocolate, lavadero y limpieza de la casa) lectura (preferiblemente del catecismo), escritura de planas y finalmente, las virtudes de la mujer cristiana sobre la virginidad, el recato, la vanidad, la ociosidad, la honestidad y el respeto a los mayores, entre otros.

Pero es en el cumplimiento de las actividades escolares inscritas a su vez en horarios de tiempo cabalmente delimitados, en donde se evidencia este proceso de modelación tanto corporal como moral del menor, como en una especie de sinfonía musical aparentemente perfecta. De esta forma en la escuela de primeras letras para niñas pobres fundada por Pedro de Ugarte (1801) se hacia la siguiente distribución de actividades por horas:

De seis a ocho levantarse, dar gracias, lavarse, oír misa, peinarse y desayunarse. De ocho a once y media el ejercicio o escuela de costura, lección doctrina y escribir. De once y media a doce diversión. De doce y media comer. De la media a la una limpiar y componer las cosas de la mesa y cocina. De una a dos diversión. De las dos a las cinco lo mismo que se ejercitó de ocho a once y media, de cinco a seis diversión. De las siete a la media lección espiritual. De seis y media a siete rosario y examen de conciencia. De siete a la media cenar. De siete y media a las ocho conversación espiritual, de ocho a la media acostarse. (Martínez Boom, 2011, p. 328)

Finalmente quisiera resaltar la articulación del enunciado moral con los tiempos que modula el horario: "se observará puntualmente el repartimiento de horas y distribución del tiempo, acomodado a la calidad y edad de las niñas de modo que no tengan ociosidad y que siempre estén ocupadas sin fatigas ni molestia, y tengan tiempo para las devociones; labores y alguna diversión honesta ${ }^{8}$. En general, todas estas prescripciones morales encaminadas a moldear a los menores como ciudadanos virtuosos se plantearon bajo los mismos parámetros tanto en las colonias americanas como en España.

\section{Geometrización del cuerpo}

Así como la escuela de primeras letras intentó constituir una ortopedia moral a los menores con el fin de que sirviesen como ciudadanos virtuosos formados en los

\footnotetext{
${ }^{8}$ Biblioteca Nacional. Sala Libros Raros y Curiosos. Protocolos. Instrucción Pública, fol 349 v. y r.
} 
preceptos de la Iglesia y el Estado, paralelamente la escuela también se propuso modelar los cuerpos de los menores para que pudieran desempeñarse en todos los espacios, dentro y fuera de la escuela, y tiempos.

Este proceso de formación física se llevó a cabo generalmente por dos vías. Una de ellas, fue el castigo corporal, que se prescribió con cierta moderación y la segunda, mediante los ejercicios físicos rutinarios destinados al cumplimiento de las diferentes actividades sociales. Ambas formas estuvieron encaminadas a infundir en el niño el control mental y espiritual sobre su cuerpo, pues se consideraba que a través de éste podían aflorar o manifestarse todos los pecados y asimismo corromperse.

Este pensamiento lo encontramos en el propio San Agustín, en particular cuando hace referencia a la concupiscencia sexual del infante desde el momento en que es amamantado. Así, se preguntaba “¿no es acaso pecado codiciar el seno llorando?” - a lo cual respondió: "Si ahora yo codiciara con ese ardor un alimento adecuado a mi edad, sería objeto de burla [...] se trata entonces de una avidez maligna, dado que al crecer la arrancamos y la rechazamos" (Agustín, 1993, p. 34).

De esta forma, se veía y prescribía como necesario someter los cuerpos de los niños "frágiles", "torpes", pero también "contaminados por el pecado" a todo un proceso de geometrización, mediante "sanas correcciones" o "castigos". Así lo contempló Vives quien al igual que Agustín, creía que el alma desenfrenada del niño podía llegar a ser piedra de tropiezo para el cuerpo:

Como el entendimiento humano a veces camina hacia el mal por la acción de las impurezas del alma, es menester reprimir y sofrenar sus movimientos irreflexivos, empleando castigos de palabras hasta azote si llega el caso, para que obre el dolor allí donde la razón no alcanza. (Vives, 1923, p. 100)

El castigo, usado en caso extremo, cumplía así más efecto que la rutina. El sendero de la rutina tuvo como centro de acción, la escritura. Pedro Díaz Morante estipuló en su manual de escritura que los niños a la par que fueran aprendiendo este arte y superando la impericia en los trazos o grafos, debían memorizar máximas morales como la siguiente: "aquel que ama verdaderamente a sus hijos, los castiga y corrige muchas veces, para que cuando sean mayores reciban placeres, y no se vean precisados a mendigar por puertas ajenas llenos de infelicidad" (Díaz, 1776, p. 30).

Para Francisco Xavier de Santiago Palomares la torpeza física de los menores, cuando se iniciaban en los rudimentos de la escritura y la lectura, no sólo debía corregirse con un número indeterminado de planas, sino con una adecuada enseñanza de la ortología o la forma de pronunciar y deletrear correctamente, con métrica, las palabras: 
Es digno de premio, y hace un gran servicio a la República el que descubra el verdadero y natural modo de enseñar a los niños las primeras letras, para desvanecer la confusión y dificultad que padecen al tiempo de aprender a leer, o pronunciar las consonantes con aquellas suavidad que lo hace el que posee la ortología. (Santiago Palomares, 1786, p. 7)

Palomares veía en la escritura más que un arte, una ciencia de exactitud y finura, detengamos en la preciosidad del detalle:

La pluma [...], según muestra la experiencia de los que poseen el arte, y se corrobora con la opinión de los autores clásicos, que han tratado de la materia, se toma con los dos primeros dedos de la mano derecha, a saber el pólice y el índice, de modo que descanse sobre el tercero, quedando suavemente asegurada como en un triangulo entre los tres, los cuales descansarán sobre el anular, y éste sobre el pequeño, o auricular. Todo esto se supone que ha de ser suavemente sin la menor violencia, para que los tres dedos que aseguran la pluma se muevan con libertad hacia todas partes, alargándose, o encogiéndose cuando convenga; y así la primera coyuntura del dedo auricular, como centro sobre que se mueven los tres dedos, debe sentarse sobre el papel. La pluma no se ha de voltear, ni torcer entre los dedos cuando se escribe, ni menos se debe oprimir con ellos contra el papel, porque si esto se hiciere, además de cansarse la mano, se gastarían los puntos de la pluma, y los gruesos y delgados de las letras no saldrían con la debida proporción. (Santiago Palomares, 1786, p. 47)

Ambos manuales de escritura, tanto el de Díaz como el Palomares, fueron adoptados como modelos a seguir por muchos maestros de primeras letras en las colonias americanas. Así Santiago de Torres al formular "las ordenanzas" que debían regir" en la escuela de primeras letras del barrio las Nieves en Santa Fe de Bogotá, en 1809 , indica taxativamente que se

enseñara a escribir por el método Palomares haciendo imitar sus muestras o las de Don Esteban Jiménez, que son del mismo estilo bajo las reglas siguientes: Principiará por enseñar teóricamente el Arte de escribir y no pondrá a hacer planas a sus discípulos hasta que sepan dar puntualmente del corte de la pluma, efectos de ésta, modo de tomarla y poner el brazo y mano sobre la mesa, caídos de la letra y sus proporciones según arte [...]. Desde la escuela de leer se les enseñará a los niños a conocer los caracteres numéricos por el mismo método que se ha prevenido para las letras y en la de escribir a formarlos [...]. Luego que sepan formar los números, y la tabla de memoria, pasarán a la clase de aritmética. (Ordenanzas que han de regir la escuela, que va a fundar en las Nieves su actual cura interino, doctor Santiago de Torres, 1809. AGN. Instrucción pública. Anexo, tomo IV, fols. 380r-397v)

Las letras son el principio de los idiomas y del lenguaje porque del unión de ellas resultan las sílabas,

y de ellas se componen las palabras con las que saca a la luz el entendimiento humano sus más ocultos pensamientos, y los afectos, ya de 
alegría, ya de temor, ya de piedad, ya de dolor, porque las letras son notas de las voces, así como lo son al profesor de música los signos musicales. (Santiago Palomares, 1786, p. 25)

Así que el conocimiento del alma, sus pasiones y sus virtudes era posible sobre todo a través de la escritura; por lo tanto habría que cultivarlo y manejarlo con el mayor de los cuidados. Su belleza depende de normas precisas que reglamenten las posiciones del cuerpo y del alma.

El maestro debería saber escribir perfectamente para poder ser imitado en sus posiciones y en sus formas. Los procedimientos que se aconsejan en la enseñanza de la escritura normatizan todos los movimientos: los ángulos que deben formar los brazos, la mirada, la luz, y en fin una correlación precisa y articulada entre cuerpo y gesto. Para que el cuerpo este subordinado al espíritu que ya ha sido a su vez preparado. He aquí un ejemplo de lo que podemos definir como escritura, en esa época.

A la pregunta formulada al maestro de Arma de Rionegro, 1806, sobre qué era escribir, éste contestó: "es poner de manifiesto por el valor de las letras y demás signos que usamos en nuestros escritos no solo lo que vemos sino lo que pensamos" (Martínez Boom, 2011, p. 191). La escritura es el vehículo del pensamiento; sólo ella puede expresar con "suficiente claridad las potencias, las virtudes, los vicios, la sabiduría, la ignorancia, la benignidad, la elocuencia, la bondad" (Santiago Palomares, 1786, p. 70).

Ese mecanismo que es capaz de manifestar los estados de ánimo del espíritu de forma mucho más evidente y precisa que cualquier otro arte requería, por tanto un supuesto y una base sólida y necesitaba una preparación muy rítmica y encadenada. Pasando entonces a elaborarse un esquema anatómico-geométrico que se ejecutará en un tiempo y un espacio delimitados y cuadriculados ${ }^{9}$.

Veamos qué responde el mismo maestro cuando le preguntan por las reglas necesarias para una buena escritura:

Que la cabeza esté levantada del cuerpo (derecho) separado un tanto de la mesa, que el brazo izquierdo sujete suavemente el papel, y le mueva cuando sea necesario, que la esquina izquierda inferior del papel mire rectamente al pecho, que la pluma y el codo del brazo derecho hagan la figura del compás para no ser tardo en escribir y últimamente que imiten la muestra. (Díaz Morante, 1776).

Como maestro, ahora de la escuela de Cartago en el Nuevo Reino de Granada en 1804 , señalaba que el método correcto para una buena escritura era que

\footnotetext{
${ }^{9}$ Esta tesis fue descrita por primera vez en un trabajo anterior: MARTíNEZ BOOM, Alberto. Escuela, maestro y métodos en Colombia, 1750-1820. Bogotá: Universidad Pedagógica Nacional, 1986. Acápite segundo sobre el arte de escribir del subtítulo: Manual y método de enseñar.
} 
los discípulos han de ver al maestro tomar la pluma y como la maneja, para que aprenda la verdadera colocación de los brazos sobre la mesa, el buen aire y gesto con que se debe escribir. La cabeza ha de estar medianamente inclinada, el pecho apartado de la mesa, la mano izquierda ha de sujetar el papel y volverle lo preciso, la esquina izquierda del papel que cae debajo de la mano que la sujeta ha de mirar a la mitad del pecho y la derecha ha de cuatro dedos más alta que la outra. (Martínez Boom, 2011, p. 136)

En síntesis, toda una gimnasia y un detalle con alto grado de precisión "cuyo código riguroso domina el cuerpo por entero, desde la punta del pie hasta la yema del dedo índice" (Foucault, 1987, p. 156). La cuadriculación del cuerpo en el proceso de la escritura es tanta que se recurre incluso a las reglas geométricas para enseñarla, al respecto podríamos dejarnos sorprender por la minucia prescriptiva del manual que advierte:

Para saber en qué lugar ha de ir sentado el dedo meñique y brazo se tirará la diagonal del dicho cuadrángulo y en ella misma ha de estar puesto el brazo y el dedo chico sobre que cargan los otros dedos, el que sirve de centro, como queda dicho, para formar las letras. (Aznar de Polanco, 1719, p. 13)

Cada trazo de letra, cada lugar del cuerpo estaba determinado y definido por unas reglas que respondían a la más minuciosa simetría en la que ningún elemento está sin cubrir.

Más que el saber, en este caso la escritura, lo que se enseña es una compostura, unos gestos, una rutina ${ }^{10}$, una etiqueta ${ }^{11}$ en fin, una disciplina. $O$ mejor, es un saber normatizado que intenta disciplinar el cuerpo. Por otro lado, con relación a la deformidad e incompletud del cuerpo del menor, se recomendaban los buenos hábitos alimenticios y los ejercicios físicos, puesto que de éstos dependían a su vez el desarrollo mental y espiritual del mismo.

Así lo estipuló Hervás y Panduro:

El hombre, que desde su infancia está poco sano en el cuerpo, lo suele estar también en el espíritu, porque obrando este con cierta dependencia

\footnotetext{
${ }^{10}$ El proceso de geometrización del cuerpo del menor no sólo se llevó acabo mediante el establecimiento de ejercicios rutinarios, sino que también fue primordial la parcelación o distribución del tiempo como ya lo anote antes. Phelipe Scio en su método uniforme para maestros aconseja que éstos cuiden que los discípulos "empleen útilmente todo el tiempo, que estuvieren en la escuela, y para esto les ha de distribuir prudentemente los ejercicios, y ocupaciones, de modo que no se verifique, que alguno pase un rato ocioso, o mano sobre mano" (Scio, 1780, p. 2). La construcción del tiempo es una constante de la documentación, construcción que va de la mano de la construcción de la subjetividad.

${ }^{11}$ Pero este manejo del cuerpo del niño también se prescribía para que tuviese incidencia o repercusión fuera de la escuela. Así, los menores debían saludar, según Santiago de Torres "a sus Padres, Maestros, Mayores, e iguales así al salir como al entrar en sus casas, en la calle y lugares públicos [...].Les advertirá [el maestro] el modo de tratar con toda clase de personas según sus diferentes dignidades, estados, y autoridades. Que la moderación aún con los inferiores es muy laudable y por el contrario muy reprensibles las alteraciones, voces desentonadas, risotadas, gesticulaciones, etc., y que lo es mucho más en la calle y lugares públicos" (AGN. Instrucción pública, anexo, t. IV, f. 385v-387r.).
} 
de la disposición y humores del cuerpo, no puede ejercitar bien sus funciones, sino es bueno el instrumento con que las ejercita. (Hervás y Panduro, 1789, p. 278)

El cuerpo será minuciosamente intervenido en la escuela, los menores debían seguir, según Hervás y Panduro, el siguiente catálogo de ejercicios que garantizaba la geometrización de su cuerpo y de sus comportamientos:

I. Los exercicios corporales necesarios, como comer, ver, dormir, etc., se deben hacer con limpieza, policía y honestidad. Si el infante come, no ha de jugar, si está en la cama, luego que despierta se ha de levantar inmediatamente, y se ha de cubrir con honestidad...

II. los infantes lávense y vistan con policía; sepan hacer por si mismos estos servicios necesarios...

III. Palabras poco civiles, o trato libre no se permitan ni por chanza. Tampoco se permita la facilidad de interrumpir los discursos o contradecir...el infante se enseñe y obligue a decir siempre: si $\mathrm{V}$ md. permite, si me da $\mathrm{V}$ md. licencia para hablar...

IV. toda libertad de manos y acciones, que es propia solamente de salvajes, en los infantes se debe reprender, y aún castigar seriamente. Si a estos se niega o manda seriamente una cosa, no se ceda jamás. Si a los infantes, por que lloran, se dexan salir con su voluntad, la condescendencia vil hace que su desobediencia sea incurable.

V. A los infantes dése idea práctica de la graduación de respetos y cumplimientos diversos que se deben a todas personas según su edad, dignidad o sexo.

VI. Sepan hacer los actos necesarios, ya preliminares y ya de despedida, que piden la urbanidad y cortesía de cuerpo y palabras respecto de las personas que visitan, encuentran casualmente, o hallan en su habitación. (Hervás y Panduro, 1789, p. 279)

De igual forma, Locke pensaba "aunque el alma sea la parte más considerable del hombre y nos debamos dedicar principalmente a su cuidado, no por esto ha de despreciarse enteramente el cuerpo, respecto la unión tan íntima que tienen entre sí" (Locke, 1767, p. 3).

Igual Scio recomendaba que el niño después de la escuela y de haber tomado alguna

ligera refacción o alimento, podrá divertirse algún rato proporcionado; y en esta hora convendrá ser la diversión de ejercicio corporal, como de pelota, volante y un rato de paseo, que será siempre con compañeros de buenas costumbres. (Scio, 1980, p. 5)

Santiago de Torres prescribió a su vez toda una serie de normas sobre el cuidado del cuerpo y el control del mismo que los menores estaban obligados a cumplir en los espacios públicos y privados. En el capítulo relacionado con Política y civilidad, Torres exaltaba al maestro para que persuadiera 
a sus discípulos a la limpieza aseo del cuerpo, y lo que a él pertenece disuadiéndolos al mismo tiempo de la novedad, capricho y afectación en el vestirse [...]. También instrúyalos de la decencia y honestidad con que se han de vestir y desnudar para levantarse y acostarse. Del mismo modo, que el maestro enseñe la templanza en el comer y beber dándoles instrucciones sobre el modo y orden de sentarse a la Mesa, que comportarse en ella, así en el repartimiento de lo que han de comer, como en el aseo. (AGN. Instrucción pública, Anexo, t. IV, f. 387r.)

De acuerdo con Amar y Borbón los vestidos de las niñas no debían ser ricos:

lo primero, por el daño que causan en lo moral, enseñándolas desde temprano a estimarlos más de lo que merecen; y lo segundo, por que se les quita la libertad de jugar, que les es tan saludable. El temor de que las riñan o castiguen si los manchan o los rompen, las obliga a estarse sentadas, y no pensar en otra cosa que en su adorno. (Amar y Borbón, 1790, p. 91)

También estipulaba que

es parte muy esencial de la limpieza no ser desaliñadas en su persona se ha de cuidar mucho de reprehender a las niñas que tuvieren este defecto, obligándolas a ir siempre bien calzadas, a llevar los alfileres precisos en pañuelo y vestido, a dejar con orden y aseo los vestidos que se quitan; y a no repugnar que las peinen y las limpien. (Idem, p. 140)

Felipe Salgar (1789) también exaltaba el aseo en los estudiantes "como una de las cosas que más recomiendan la persona" y por tanto,

deberán los muchachos de la escuela presentarse en ella todos los días con la cara y manos lavadas perfectamente; de que cuidará el celador como uno de los puntos más esenciales de la educación. Y como entre la gente de este lugar, muchos o los más, no usan medias ni zapatos, cuidará también de que no entren a la escuela sin haberse compuesto primero el cabello, juagado los pies, las piernas y cortado las uñas. Sería de desear que ya que no alcanzan estas gentes a comprar el zapato, usen por lo menos de alpargate, con que evitarían la deformidad del pie y añadirían nueva decencia a su persona. (Citado en Hernández, 1983, p. 179)

Otra forma de castigo que buscó modelar el cuerpo del estudiante, aunque censurada por los tratadistas de la educación, fue la ridiculización o el escarnio público del estudiante ante la falta o trasgresión por parte de éste de los reglamentos escolares o el mismo sistema de valores estipulado en estos recintos. Por ejemplo, el mismo Simón Rodríguez contempló los "casos en que deben ser expelidos los discípulos de las escuelas":

Primero: cuando los padres coartan a los maestros la facultad de corregirles los defectos en que incurran. Segundo: cuando son obstinados en vicio escandaloso. Tercero: cuando maliciosamente falten al respeto que deben a los maestros. Cuarto: cuando sean díscolos, chismosos o 
revoltosos. Quinto: cuando deserten de las escuelas con consentimiento de sus padres, sin causa legítima. (Rodríguez, 1999, p. 2209)

Pero así como existió el castigo físico o moral en las escuelas para los trasgresores del orden, también se contempló el premio o la exaltación por la labor cumplida como medio de construir no sólo el cuerpo, sino al niño en su integridad. Felipe Salgar (1789) refería "que para el gobierno de los hombres son precisos el premio y la pena", pero

para excitar más y más en los niños el deseo de la perfección, así en la lectura como en la escritura, deberá el maestro repartir algunas gracias entre aquellos discípulos que en una u otra materia manifiesten más habilidad y talentos. (Hernández de Alba, 1983, p. 178)

Por su lado, Santiago Delgado de Jesús en la cartilla precisa y necesaria prescribía que los padres y ayos no tenían necesidad de excederse en los castigos y sólo aconsejaba

usar mas que de privaciones de ciertos gustos en la comida, diversión, vestido, salidas, condescendencia a la visita, etc., y sobretodo el negarles sus padres su vista por algún tiempo, hasta lograr su corrección. Lo mismo decimos para premiar y alentar su espíritu a los adelantamientos y progresos en su instrucción física, moral o científica. (Hernández de Alba, 1983, p. 178)

A lo sumo, la educación de primeras letras impartida por los maestros a sus discípulos fue una combinación entre ortopedia moral y geometrización corporal ${ }^{12}$, con el propósito de construir una nueva y particular subjetividad, la del ciudadano moderno; subordinado a interactuar en espacios urbanos cada vez más cerrados y en periodos de tiempo fraccionados para el cumplimiento de las diversas tareas cotidianas.

\section{De la quietud corporal a la obediencia}

Todos los manuales, métodos, cartillas o planes de escuela de primeras letras estuvieron encaminados a instruir al menor partiendo del principio de quietud del cuerpo y una vez conseguido éste, podía impartirse el disciplinamiento de los menores en los tres órdenes: espiritual, mental y corporal. Para Vives el principal "órgano de la enseñanza" era el "oído" y por tanto, el maestro debía cultivar y afinar dicha facultad entre sus

\footnotetext{
${ }^{12}$ Esta combinación de preceptos que el maestro debía transmitir a sus alumnos, se pone evidencia en los "exámenes de oposición". Así para optar al cargo de maestro Rionegro, en 1807, el cabildo le pregunta Joseph Miguel Álvarez, otro de los aspirantes al magisterio de primeras letras, "cuáles son las principales obligaciones del maestro?" Este respondió: "estar asistente en la escuela, llevar los niños a misa, propender a que estén aseados, enseñarles a leer, escribir y las cinco reglas y algunas partes de la ley antigua, la luz de gracia y evangelio que confiesen y comulguen cada mes, doctrina cristiana, respeto y subordinación a sus padres al maestro y mayores" (AGN, Instrucción pública, anexo, t. VI, f. 436 y 437 r).
} 
discípulos con el propósito de conseguir la quietud del cuerpo; como punto de partida del proceso de instrucción y progresivamente, el cabal aprendizaje de las ciencias y las artes.

Si hablamos de Vives aquí, nos referimos a él por el dialogo que estos nuevos tratados entablaron con sus obras. De este modo,

debe el niño escuchar con atención, mirando al maestro cuando no tenga que leer o escribir, [pues] nada es más rápido y provechoso que oír mucho; todo cuanto se escuche al profesor debe tenerse como oráculo completo y perfecto, en cualquier aspecto que sea. (Vives, 1923, p. 89)

Phelipe Scio prescribió que no sólo "en la escuela [el menor] oirá con atención" para que pueda llevar a buen término su instrucción, sino también guardará "compostura de alma, y cuerpo" en aras de reprimir comportamientos indecorosos e impúdicos que sirvan de "piedra de tropiezo" para el que los propugna. De tal forma que el discípulo "responderá, y hará las tareas, que les ordene su maestro con prontitud, modo, y claridad". Advirtiendo finalmente que éste "no hablará, o jugará de manos, o por señas ridículas con los compañeros. Y sepa, que todo esto, el hablar a otro al oído, o en secreto, o cuando habla el maestro, u otro, es una grosería incivil, e insufrible" (Scio, 1780, p. 3).

Según Felipe Salgar, el bullicio de los niños debía "suprimirse por completo de las escuelas, pues se ignora de dónde ha dimanado la práctica bárbara que los escolares aprendan sus lecciones en voz alta y desentonada". La grita de todos "los confunde necesariamente y los que están escribiendo son perturbados más que otro alguno con semejante confusión", por tanto, "se guardará pues el silencio correspondiente en la escuela: leyendo paso los que no escriban y éstos no hablando entre sí", sino con la "debida modestia aquéllos que sea muy preciso. De este modo se evitará el desorden que ha reinado por tanto tiempo". (Hernández de Alba, 1983, p. 179).

La consigna de hacer silencio avocará al maestro a una tarea disciplinaria ${ }^{13}$. Es también la primera acción que pone en disposición al estudiante, pues lo que se enseña tiene que ser en primer lugar escuchado; en otras palabras, se aprendía de oído y sin silencio no había aplicación. La idea en general, era la de erradicar de la escuela los comportamientos inmorales, toscos, montaraces o silvestres con el ánimo de que reinara el silencio en la escuela.

\footnotetext{
${ }^{13}$ Los cuerpos disciplinados de los estudiantes debían comportar esta práctica en otros espacios sociales. Igual comportamiento se esperaba que guardaran en la iglesia: "si reza algunas oraciones, o lee algún libro piadoso, no lo haga en voz sensible, de modo que sirva a los otros de distracción, o se haga sospechoso de una afectada hipocresía [...] Les enseñará [el maestro] la compostura, reverencia y sumo respeto con que han de entrar en el templo y asistir a los Santos sacrificios y actos de Religión" (Scio, 1780 , p. 5).
} 
También las niñas estaban obligadas a guardar silencio y compostura "en todos los actos de comunidad como es cuando tengan que salir de casa, al tiempo del desayuno, comida y cena"14, en la escuela debían permanecer en completa "quietud y aplicación [...] en las horas destinadas para el trabajo de manos, lectura y planas" y en caso de desacato, darles "siempre que lo necesiten saludables correcciones, y no bastando éstas, un moderado castigo para su enmienda".

En general se estipuló que el maestro de primeras letras estaba en la obligación de vigilar constante y celosamente "la regularidad, el silencio y la buena crianza" entre sus discípulos" (Caballero y Góngora, 1787), una vez conseguidos estos principios podrá finalmente el maestro "imprimir de tal modo en sus tiernos espíritus el amor a la virtud, a las ciencias y conocimientos útiles" (Idem).

A lo sumo, es mediante la instrucción, según Jovellanos, que el disciplinamiento de los cuerpos y de las almas de los menores podía llevarse a buen término, pues "la educación es un bello barniz de la instrucción y su mejor ornato, pero sin la instrucción no es nada, es solo apariencia. La urbanidad dora la estatua, la instrucción la forma" (Jovellanos, 1845). Así se fue diferenciando educación de instrucción: la primera es arreglo la segunda es disposición.

De ahí que "cuanto menos juicio tengan los [menores], tanto más es necesario que estén sometidos al poder y dirección absoluta a quienes estén encargados", es decir que "con cuanta más anticipación se principie a sujetarlos, con tanta más facilidad se podrá hacerles ejecutar las cosas, y tantas menos dificultades tendrán que vencer los ayos" (Locke, 1767, p. 87). Igualmente acentuaba el papel de la autoridad del padre y del maestro, de ahí que recomendara que los padres de los menores que

deben principiar sometiéndolos a su voluntad cuando sean pequeños ¿Queréis que vuestro hijo sea obediente, después que haya salido de la infancia? Haced valer vuestra autoridad de padre desde el punto que esté capaz de someterse y poder comprender de quien depende [...]. Si se tiene pues cuidado de reprimirlos en los primeros años, se someterán sin violencia a este tratamiento, pues no han conocido ningún otro; y si cuando ya principiarán a usar de su razón, modera su severidad al padre poco a poco y les abre su comunicación más francamente, según vayan siendo dignos, el miedo respetuoso en que antes han estado, servirá sólo para dar nuevo aumento a su cariño. (Locke, 1767, p. 88)

Así como los monasterios han formado a los monjes, los ejércitos a los soldados o las fábricas a los obreros, las escuelas de primeras letras también empezaron a moldear subjetividades obedientes.

\footnotetext{
${ }^{14}$ Biblioteca Nacional. Sala Libros Raros y Curiosos. Protocolos. Instrucción Pública, fol 349r.
} 
El examen de estas prácticas sirve también en otras direcciones, por ejemplo, en relación a la formación de los menores en las ciencias y las artes. Se obedece no sólo al maestro y a la autoridad, sino al saber o como lo decía Huarte, al ingenio: "antes que el muchacho se ponga a estudiar, descubrirle la manera de su ingenio y ver cual de las ciencias viene bien con su habilidad" (Huarte, 1976, p. 73), pues según él, a cada hombre le correspondía un sólo tipo de ingenio, con el cual podría desarrollar no más que una ciencia.

De esta forma, únicamente se podía tener habilidad para lo teórico o para lo práctico, pero no para ambas cosas a la vez ${ }^{15}$. Por tanto, "si no aciertas a elegir la que responde a tu habilidad natural, [tendrás] de las otras gran remisión aunque trabajes días y noches". De tal suerte,

te queda otra dificultad mayor por averiguar; y es si tu habilidad es más acomodada a la práctica que a la teórica, por que estas dos partes, en cualquier género de letras que sea, son tan opuestas entre si y piden tan diferentes ingenios, que la una y la otra se remiten como si fueran verdaderos contrarios. (Huarte, 1976, p. 65)

Si se pregunta alguien que se hace en la escuela, probablemente señale leer, escribir, los contenidos, etc., pero en realidad lo que están aprendiendo es el hábito que forma al sujeto siempre en disposición. En este sentido, el sujeto no es una sustancia sino una forma vacía pero sujeta a transformaciones. El sujeto o la forma sujeto son producto de todo este conjunto de ejercicios, de unas relaciones en las que cierto saber define que hay que hacer, o mejor un saber dirige el ejercicio a partir del cual se constituyen unas sujeciones.

Una vez visto el estado fragmentario de la escolarización en la segunda mitad del siglo 18, resulta útil reconocer como en las colonias americanas se generalizaron manuales, métodos, proclamas, catecismos y obras ejemplares que fueron tejiendo un conjunto de procedimientos regulativos que hacían del cuerpo infantil y de la escuela un lugar sitiado, protegido y tutelado a través de prácticas bastante contingentes.

En términos generales podemos decir que la escolarización dispone, prepara, anticipa, pone a discreción cuerpos, gestos y acciones posibles. Para ello utiliza instituciones, programas y planes que iniciando en la documentación aquí trabajada llega,

15 Con esto, Huarte de San Juan quería evitar "que el carpintero no hiciese obra tocante al oficio de labrador, ni el tejedor del arquitecto, ni el jurisperito curase, ni el médico abogase; sino que cada uno ejercitase sola aquel arte para la cual tenía talento natural y dejase las demás [...].Y, por que no errase en elegir la que a su natural estaba mejor, había de haber diputados en la república, hombres de gran prudencia y saber, que en la tierna edad descubriesen a cada uno su ingenio, haciéndole estudiar por fuerza la ciencia que le convenía, y no dejarlo a su elección" (Huarte, 1976, p. 61). 
hoy por hoy, a articular una idea de escolarización moderna, cuya definición es bastante más amplia. En un trabajo reciente expuse que entendía por escolarización:

1. El conjunto de instituciones, procedimientos, reflexiones, prácticas y tácticas que tienen por blanco la producción de sociedad escolarizada; 2. La preeminencia de la forma escolar como aparato de control que construye aparatos de gobierno y formas de saber; 3 . Es un dispositivo de distribución, producción y reorganización de la población, en la que ésta se dispone en términos de generación de sujetos dotados de herramientas, habilidades, competencias, etc.; 4. Es el cruce de líneas de fuerza que permite comprender los fenómenos de la educación y de su crisis en doble dirección: hacia arriba, porque es la sociedad la que demanda más educación, y hacia abajo, ya que la generación de necesidades educativas afecta todos los ámbitos de lo social. (Martínez y Orozco, 2010: 113)

\section{Referências}

AGUSTÍN, San. Confesiones. Barcelona: Altaya, 1993.

AMAR Y BORBÓN, Josefa. Discurso sobre la educación física y moral de las mujeres. Madrid: Imprenta de Benito Cano, 1790.

ARIĖS, Philippe. El niño y la vida familiar en el Antiguo Régimen. Madrid: Taurus, 1987.

AZNAR DE POLANCO, Juan Claudio. Arte nuevo de escribir por preceptos geométricos y reglas matemáticas. Madrid: Manuel Ruiz de Murga, 1719.

CABALLERO Y GÓNGORA, Antonio. Plan de universidad y estudios generales. Tomo 2, fol. 210r. Bogotá: Archivo General de la Nación, Fondo de Instrucción Pública, 1787.

DÍAZ MORANTE, Pedro. Nueva arte de escribir inventada por el maestro Pedro Díaz Morante. Madrid: Librería de Antonio de Sancha, 1776.

DONZELOT, Jacques. La policía de las familias. Valencia: Pre-Textos, 1879.

FOUCAULT, Michel. La vida de los hombres infames. La Plata: Altamira, 1996.

FOUCAULT, Michel. Vigilar y castigar: nacimiento de la prisión. México: Siglo 21, 1987.

HERNÁNDEZ DE ALBA, Guillermo. Documentos para la historia de la educación en Colombia, 1777-1800. Tomo V. Bogotá: Nelly, 1983.

HERVÁS Y PANDURO, Lorenzo. Historia de la vida del hombre. Madrid: Imprenta de Aznár, 1789.

HUARTE DE SAN JUAN, Juan. Examen de ingenios para las ciencias. Madrid: Nacional, 1976.

JOVELLANOS, Gaspar Melchor de. Obras. Madrid: Editor D. F. de P. Mellado, 1845.

LOCKE, Mr. Educación de los niños. Tomo I. Madrid: Imprenta de Manuel Álvarez, 1767.

MARTíNEZ BOOM, Alberto. Memorias de la escuela pública: expedientes y planes de escuela en Colombia y Venezuela, 1774-1821. Bucaramanga: UIS, 2011.

MARTÍNEZ BOOM, Alberto y OROZCO, Jhon Henry. Políticas de escolarización en tiempos de multitud. Revista Educación y Pedagogía, v. 22, n. 58. Medellín: Universidad de Antioquia, 2011, p. 105-119. 
MARTÍNEZ BOOM, Alberto. Escuela, maestro y métodos en Colombia, 1750-1820. Bogotá: Universidad Pedagógica Nacional, 1986.

RODRÍGUEZ, Simón. Obras completas. Tomo I. Caracas: Presidencia de la República, 1999.

RODRÍGUEZ DE CAMPOMANES, Pedro. Discurso sobre la educación popular de los artesanos y su fomento. Madrid: Nacional, 1978.

ROLIN, Carlos. Educación y estudios de los niños, y niñas, y jóvenes de ambos sexos. Madrid: Imprenta de Don Manuel Martín, 1781.

ROLIN, Carlos. Modo de enseñar y estudiar las bellas letras, para ilustrar el entendimiento y rectificar el corazón. Tomo I. Madrid: Imprenta del Mercurio, 1755.

SANTIAGO PALOMARES, Francisco Xavier de. El maestro de leer. Madrid: Antonio de Ancha, 1786.

SCIO DE SAN MIGUEL, Phelipe. Método uniforme para las escuelas de cartilla, deletrear, leer, escribir, aritmética, gramática castellana, y ejercicios de Doctrina Cristiana, cómo se practica por los padres de las escuelas pías. Madrid: Imprenta de Pedro Marín, 1780.

VARELA, Julia; ÁLVAREZ URÍA, Fernando. Arqueología de la escuela. Madrid: La Piqueta, 1991.

VIVES, Juan Luís. Tratado de la enseñanza. Madrid: La Lectura, 1923.

\section{Fuentes de archivo documental}

Archivo General de la Nación. Bogotá. Sección Colonia. Fondo Colegios.

Archivo General de la Nación. Bogotá. Sección Colonia. Fondo Conventos.

Archivo General de la Nación. Bogotá. Sección Colonia. Fondo Instrucción Pública.

Biblioteca Nacional. Sala Libros Raros y Curiosos. Bogotá. Protocolos. Instrucción Pública.

ALBERTO MARTÍNEZ BOOM é professor na Universidad Pedagógica Nacional Bogotá, Colômbia.

Endereço: Calle 128B, n. 60-04 - apto 403 - Urbanizacion Sutileza - Bogota Colômbia.

E-mail:almarboom@yahoo.com.

Recebido em 10 de março de 2012.

Aceito em 13 de junho de 2012. 